\title{
Effect of adding hydrochlorothiazide to usual treatment of patients with acute decompensated heart failure: a randomized clinical trial
}

\section{Diogo Piardi}

Federal University of Rio Grande do Sul

Mauricio Butzke

Hospital de Clínicas de Porto Alegre

Ana Carolina Mazzuca

Hospital de Clínicas de Porto Alegre

Bruna Gomes

Federal University of Rio Grande do Sul

\section{Sofia Alves}

Federal University of Rio Grande do Sul

\section{Bruno Kotzian}

Federal University of Rio Grande do Sul

Eduarda Ghisleni

Federal University of Rio Grande do Sul

Vanessa Giaretta

Hospital de Clínicas de Porto Alegre

Priscila Bellaver

Federal University of Rio Grande do Sul

Gabrielle Varaschin

Federal University of Rio Grande do Sul

Arthur Garbin

Federal University of Rio Grande do Sul

Luís Beck-da-Silva ( $D$ luisbeckdasilva@gmail.com )

Federal University of Rio Grande do Sul

\section{Research Article}

Keywords: Heart failure, furosemide, hydrochlorothiazide.

Posted Date: February 5th, 2021

DOl: https://doi.org/10.21203/rs.3.rs-150836/v1 
License: (c) (i) This work is licensed under a Creative Commons Attribution 4.0 International License. Read Full License

Version of Record: A version of this preprint was published at Scientific Reports on August 13th, 2021. See the published version at https://doi.org/10.1038/s41598-021-96002-6. 


\section{Abstract \\ Introduction:}

Acute decompensated heart failure (ADHF) is the leading cause of hospitalization in patients aged 65 years or older, and most of them present with congestion. The use of hydrochlorothiazide (HCTZ) may increase the response to loop diuretics.

\section{Objective}

To evaluate the effect of adding HCTZ to furosemide on congestion and symptoms in patients with ADHF.

\section{Methods}

This randomized clinical trial compared HCTZ $50 \mathrm{mg}$ versus placebo for 3 days in patients with ADHF and signs of congestion. The primary outcome of the study was daily weight reduction. Secondary outcomes were change in creatinine, need for vasoactive drugs, change in natriuretic peptides, congestion score, dyspnea, thirst, and length of stay.

\section{Results}

Fifty-one patients were randomized -26 to the HCTZ group and 25 to the placebo group. There was a trend towards additional weight reduction in the HCTZ group (HCTZ: $-1.78 \pm 1.08 \mathrm{~kg} /$ day vs placebo: $-1.05 \pm 1.51 \mathrm{~kg} /$ day; $p=0.062$ ). In post hoc analysis, the HCTZ group demonstrated significant weight reduction for every $40 \mathrm{mg}$ of intravenous furosemide (HCTZ: $-0.74 \pm 0.47 \mathrm{~kg} / 40 \mathrm{mg}$ vs placebo: $-0.33 \pm$ $0.80 \mathrm{~kg} / 40 \mathrm{mg} ; \mathrm{p}=0.032$ ). There was a trend to increase in creatinine in the HCTZ group (HCTZ: $0.50 \pm$ 0.37 vs placebo: $0.27 \pm 0.40 ; p=0.05$ ) but no significant difference in onset of acute renal failure (HCTZ: $58 \%$ vs placebo: $41 \% ; p=0.38$ ). No differences were found in the remaining outcomes.

\section{Conclusion}

There was a trend towards greater daily weight reduction in the HCTZ group. In analysis adjusted to the dose of intravenous furosemide, adding HCTZ $50 \mathrm{mg}$ to furosemide resulted in a significant synergistic effect on weight loss.

\section{Key Points}


Loop diuretics play the leading role in the treatment of acute decompensated heart failure, because of their association with improved signs and symptoms. However, diuretic resistance can occur in long-term use, leading to higher doses of loop diuretics, which may be associated with adverse outcomes. Adding hydrochlorothiazide (HCTZ) to loop diuretics can be an alternative to lower the dose needed and achieve better outcomes.

There was a trend towards greater daily weight reduction in the HCTZ group. For every $40 \mathrm{mg}$ of intravenous furosemide prescribed, adding HCTZ $50 \mathrm{mg}$ resulted in a significant and synergistic effect on weight loss.

\section{Introduction}

Acute decompensated heart failure (ADHF) is the leading cause of hospitalization in patients aged 65 years or older (1), accounting for approximately 800,000 admissions in the United States, with a substantial impact on both morbidity and mortality (2). According to estimates, 1 every 2 patients is readmitted within 6 months with in-hospital mortality ranging from 4 to $12 \%$. In Brazil, mortality rates are even higher $(3,4)$. Following hospital discharge, $35 \%$ of patients with ADHF are estimated to die within 1 year $(5,6)$.

ADHF may have different presentations, and patients most commonly present with congestion (7). Given its association with poor renal function, congestion may have therapeutic and prognostic implications, especially when sustained (8). This is possibly due to increased systemic and portal venous pressure, ascites, and increased intra-abdominal pressure, leading to cardiorenal syndrome $(9,10)$.

Loop diuretics act on the sodium-potassium-chloride ( $\mathrm{Na}-\mathrm{K}-2 \mathrm{Cl}$ ) cotransporter in the thick ascending limb of the loop of Henle and produce diuresis by blocking sodium reabsorption (11). They play the leading role in the treatment of congestion, being used in more than $90 \%$ of patients hospitalized with heart failure (12) because of their association with improved signs and symptoms. In addition to their diuretic effect, loop diuretics produce vasodilation on smooth muscle cells in the vessels. There is also an effect on the activation of the renin-angiotensin-aldosterone system (RAAS), which has a positive side, i.e., adjustment of the glomerular flow in the nephron, and a negative side, i.e., neurohumoral activation leading to the perpetuation of deleterious effects on the patient with heart failure (11).

However, long-term use of diuretics in patients with ADHF is quite common, generating potential mechanisms of diuretic resistance, in which the diuretics do not achieve the desired effect, manifested by low urine sodium concentrations despite the recommended maximum doses. Several mechanisms have been proposed to explain such process, including reduced diuretic efficacy, salt retention, rebound effect, and nephron remodeling $(5,11,13)$. Also, high doses may be associated with adverse outcomes (14). An alternative approach used in clinical practice is sequential nephron blockade, which consists of the combination of diuretic classes, such as loop and thiazide diuretics, acting on the distal convoluted tubule, and aldosterone antagonists, acting on the collecting duct (12). 
In the DOSE (Diuretic Strategies in Patients with Acute Decompensated Heart Failure) trial (15), there was an absolute increase in the use of thiazide diuretics by $11 \%$, as well as a trend towards a greater use of thiazide diuretics in patients on low-dose loop diuretics. However, less than 400 patients have been included to date in studies, mostly observational, assessing the combination of diuretics in patients with ADHF (5). Thus, the present study aimed to evaluate the effect of hydrochlorothiazide (HCTZ) added to furosemide versus furosemide alone on congestion, measured by weight reduction, in patients with ADHF.

\section{Methods}

\section{Study design}

A randomized, single-center, parallel, double-blind, placebo-controlled clinical trial was conducted.

\section{Participants}

Patients admitted to the emergency department at Hospital de Clínicas de Porto Alegre, southern Brazil, with $A D H F$ and systolic dysfunction (ejection fraction $[E F] \leq 45 \%$ ) were included if they met the following criteria: age $\geq 18$ years, diagnosis of ADHF, emergency department admission < 18 hours, endogenous creatinine clearance $>30 \mathrm{~mL} / \mathrm{min}$, serum potassium ranging from 3.5 to $5.1 \mathrm{mEq} / \mathrm{L}$, and signs of congestion. Congestion was based on the presence of at least two of the following: lower limb edema; crackles on lung auscultation or chest radiogram with signs of congestion; jugular vein distention or hepatojugular reflux; weight gain $>4.5 \mathrm{~kg}$ compared to usual weight; orthopnea and/or paroxysmal nocturnal dyspnea.

Patients were excluded if they had serum sodium > $145 \mathrm{mEq} / \mathrm{L}$, Bartter or Gitelman syndrome, type IV renal tubular acidosis, history of sulfa allergy, current acute coronary syndrome, previous history of gout, pregnancy or lactation, associated septic shock, liver dysfunction (defined as elevated transaminases three times above the reference value), or inability for enteral intake. The study was approved by the Hospital de Clínicas de Porto Alegre Research Ethics Committee (number 45773815.7.0000.5327) and was performed in accordance with the relevant guidelines and regulations.

\section{Intervention and logistics}

Patients were invited to participate if they met the inclusion criteria for the study and had no exclusion criteria. After signing a written informed consent by the patient or a legally authorized representative, the enrolled patients were randomly allocated to two groups: HCTZ 50 mg or placebo (both oral). Dose of intravenous furosemide and additional therapies were at the discretion of the patient's medical team. The duration of the intervention was 3 days or until hospital discharge if occurring before 3 days of admission (Fig. 1).

An external investigator using a web-based software generated randomized sequences, divided in two blocks, and the resulting spreadsheet was sent to the pharmacist responsible for medications - HCTZ 50 mg and placebo, both stored inside identical numbered vials - and who had no scientific involvement in 
the study (Spengler Pharmacy, Porto Alegre, Brazil). All investigators and patients were blinded to the treatment assignment.

Figure 1: Logistics and interventions

S: screening; E: enrollment; R: randomization; PO: oral administration; QD: once daily

\section{Follow-up}

Patients were monitored as follows (Fig. 2):

- Day 0: patient inclusion, randomization, drug administration, assessment of clinical variables, patient weighing, and baseline laboratory tests.

- Days 1 and 2: patient reassessment, order for laboratory tests, review of safety outcomes, drug administration, patient weighing, and reassessment of interventions.

- Day 3: patient reassessment, order for laboratory tests, review of safety outcomes, drug administration, patient weighing, and reassessment of interventions.

- Discharge: review of safety outcomes, length of stay.

Figure 2: Study flow diagram

\section{Outcomes}

The primary outcome of the study was daily weight change for 3 days, measured daily on the same scale (Mallory, Maranguape, Brazil). The secondary outcomes were change in creatinine, need for vasoactive drugs (sodium nitroprusside, nitroglycerin, dobutamine, milrinone, vasoactive amines), change in natriuretic peptides, congestion score (16), dyspnea scale (Likert-type), thirst scale, and length of stay. Finally, safety outcomes were in-hospital mortality, hypernatremia (sodium $>145 \mathrm{mEq} / \mathrm{L}$ ), hypokalemia (potassium $<3.5 \mathrm{mEq} / \mathrm{L}$ ), hyperkalemia (potassium $>5.5 \mathrm{mEq} / \mathrm{L}$ ), increase in creatinine $>0.3 \mathrm{mg} / \mathrm{dL}$, and ventricular arrhythmias.

\section{Sampling}

Sample size was calculated using WinPepi, version 11.1 (www.brixtonhealth.com/pepi4windows.html). Based on a study conducted by Dormans et al. (17), the statistical parameters used were an estimated weight loss of $0.5 \mathrm{~kg}$ per day for a total of $1.5 \mathrm{~kg}$ within 3 days, a power of $80 \%$ and a significance level of 0.05 , standard deviations of $0.3 \mathrm{~kg}$ in the control group and $0.8 \mathrm{~kg}$ in the intervention group, and possible loss to follow-up. Thus, the minimum sample required was 50 patients.

\section{Statistical analysis}

Data were reported as mean and standard deviation, except for asymmetric variables, which were described as median and interquartile range. Student's t-test and analysis of variance (ANOVA) were used 
for parametric variables, as appropriate. Mann-Whitney $\mathrm{U}$ and Kruskal-Wallis tests were used for nonparametric variables. For categorical variables, chi-square and Fisher's exact tests were used as appropriate. All analyses were based on intention-to-treat principles. Analyses were performed using SPSS, version 18.0 (SPSS Inc., Chicago, USA).

\section{Results}

In this study, 312 patients were screened from September 2015 to December 2019, and 52 patients met the inclusion criteria, reaching the required sample size. One patient was excluded before randomization because of gastrointestinal bleeding. Fifty-one patients were randomized -26 to the intervention group and 25 to the control group (Fig. 1). Patients were mostly white, and their mean age was 64 years. Most of them had hypertension, moderate ventricular dysfunction, history of smoking, and preserved renal function (Table 1; Table 2). 
Table 1

Demographic and clinical characteristics

\begin{tabular}{|c|c|c|c|}
\hline Characteristic & $\operatorname{HCTZ}(n=26)$ & Placebo $(n=25)$ & p-value \\
\hline Age (years) & $64 \pm 16$ & $64 \pm 10$ & 0.94 \\
\hline Male gender (\%) & 69 & 48 & 0.12 \\
\hline White race (\%) & 92 & 76 & 0.14 \\
\hline Baseline NYHA & $2.7 \pm 0.8$ & $2.3 \pm 0.9$ & 0.11 \\
\hline Ischemic etiology (\%) & 50 & 44 & 0.67 \\
\hline Hypertension (\%) & 73 & 72 & 0.93 \\
\hline Diabetes mellitus (\%) & 27 & 44 & 0.20 \\
\hline Ejection fraction (\%) & $30 \pm 8$ & $31 \pm 10$ & 0.50 \\
\hline ICD (\%) & 7.7 & 12 & 0.67 \\
\hline CRT (\%) & 0 & 4 & 0.49 \\
\hline Atrial fibrillation (\%) & 39 & 44 & 0.69 \\
\hline Previous stroke (\%) & 15 & 20 & 0.73 \\
\hline Current/past smoking (\%) & 65 & 60 & 0.69 \\
\hline Beta-blocker (\%) & 85 & 80 & 0.73 \\
\hline ACEI/ARB (\%) & 92 & 76 & 0.14 \\
\hline Outpatient furosemide (mg) & $58 \pm 57$ & $75 \pm 73$ & 0.50 \\
\hline Outpatient spironolactone (mg) & $8 \pm 12$ & $14 \pm 15$ & 0.15 \\
\hline Weight (kg) & $81 \pm 25$ & $78 \pm 19$ & 0.65 \\
\hline Systolic blood pressure (mm Hg) & $117 \pm 17$ & $122 \pm 22$ & 0.32 \\
\hline Diastolic blood pressure (mm Hg) & $72 \pm 14$ & $73 \pm 13$ & 0.91 \\
\hline Heart rate $(\mathrm{bpm})$ & $85 \pm 19$ & $91 \pm 21$ & 0.31 \\
\hline Sodium (mEq/L) & $140 \pm 4$ & $139 \pm 3$ & 0.41 \\
\hline Potassium (mEq/L) & $4.5 \pm 0.5$ & $4.6 \pm 0.5$ & 0.43 \\
\hline Urea $(\mathrm{mg} / \mathrm{dL})$ & $50 \pm 23$ & $54 \pm 18$ & 0.55 \\
\hline \multicolumn{4}{|c|}{ Plus-minus values are means \pm standard deviation. } \\
\hline $\begin{array}{l}\text { ACEl: angiotensin-converting enzyr } \\
\text { resynchronization therapy; ICD: im } \\
\text { Association classification. }\end{array}$ & $\begin{array}{l}\text { r; ARB: angioter } \\
\text { cardioverter-defil }\end{array}$ & $\begin{array}{l}\text { receptor blocker; Cl } \\
\text { or; NYHA: New York }\end{array}$ & $\begin{array}{l}\text { irdiac } \\
t\end{array}$ \\
\hline
\end{tabular}




\begin{tabular}{|lccc|}
\hline Characteristic & HCTZ $(\boldsymbol{n = 2 6 )}$ & Placebo $(\boldsymbol{n}=25)$ & $\boldsymbol{p}$-value \\
\hline Creatinine $(\mathrm{mg} / \mathrm{dL}$, mean $\pm \mathrm{SD})$ & $1.23 \pm 0.29$ & $1.24 \pm 0.34$ & 0.94 \\
\hline Plus-minus values are means \pm standard deviation. & & \\
\hline $\begin{array}{l}\text { ACEl: angiotensin-converting enzyme inhibitor; ARB: angiotensin II receptor blocker; CRT: cardiac } \\
\text { resynchronization therapy; ICD: implantable cardioverter-defibrillator; NYHA: New York Heart } \\
\text { Association classification. }\end{array}$ & \\
\hline
\end{tabular}

Figure 3: Study flow diagram

Table 2

Therapies during the study

\begin{tabular}{|llll|}
\hline Medication & HCTZ $(\boldsymbol{n}=26)$ & Placebo $(\boldsymbol{n}=25)$ & $\boldsymbol{p}$-value \\
\hline Endovenous furosemide (total, mg) & $259 \pm 143$ & $246 \pm 141$ & 0.62 \\
\hline Spironolactone (total, $\mathrm{mg})$ & $26 \pm 31$ & $28 \pm 37$ & 0.94 \\
\hline Norepinephrine (\%) & 3,8 & 0 & 1,00 \\
\hline Sodium nitroprusside (\%) & 7,7 & 4,0 & 1,00 \\
\hline Milrinone (\%) & 3,8 & 0 & 1,00 \\
\hline Endovenous nitroglycerin (\%) & 7,7 & 8,0 & 1,00 \\
\hline Plus-minus values are means \pm standard deviation. & & \\
\hline
\end{tabular}

Regarding the primary outcome, there was a trend towards greater weight reduction in the HCTZ group compared to the placebo group (HCTZ: $-1.78 \pm 1.08$ vs placebo: $-1.05 \pm 1.51 \mathrm{~kg} / \mathrm{day} ; \mathrm{p}=0.062$ ) (Table 2 , Fig. 2). For the ratio between total weight loss and total prescribed dose of intravenous furosemide, a post hoc analysis showed a statistically significant additional reduction for every $40 \mathrm{mg}$ of intravenous furosemide (HCTZ: $-0.74 \pm 0.47 \mathrm{~kg} / 40 \mathrm{mg}$ vs placebo: $0.33 \pm 0.80 \mathrm{~kg} / 40 \mathrm{mg} ; \mathrm{p}=0.032$ ) (Fig. 3). 
Table 3

Study outcomes

\begin{tabular}{|llll|}
\hline Outcome & HCTZ & Placebo & p-value \\
\hline Primary & & & \\
\hline Weight change/day & $-1.78 \pm 1.08$ & $-1.05 \pm 1.51$ & 0.062 \\
\hline Secondary & & & \\
\hline Length of stay (days) & $9 \pm 8$ & $8 \pm 9$ & 0.37 \\
\hline Change in creatinine (mg/dL) & $0.50 \pm 0.37$ & $0.27 \pm 0.40$ & 0.05 \\
\hline Need for vasoactive drugs (\%) & 19.2 & 12.0 & 0.70 \\
\hline Congestion score & $-5.4 \pm 4.6$ & $-4.8 \pm 4.6$ & 0.68 \\
\hline Change in dyspnea scale & $-4.7 \pm 2.7$ & $-3.2 \pm 3.6$ & 0.14 \\
\hline Thirst scale & $-1.7 \pm 4.5$ & $0.5 \pm 3.8$ & 0.21 \\
\hline Change in natriuretic peptides (\%) & $-11.1 \pm 100.3$ & $-33.3 \pm 50.9$ & 0.83 \\
\hline Safety & & & \\
\hline In-hospital mortality (\%, [n]) & $3.8(1)$ & $0(0)$ & 1.00 \\
\hline Hypernatremia (\%) & 0 & 4.8 & 0.47 \\
\hline Hypokalemia (\%) & 3.8 & 4.5 & 1 \\
\hline Hyperkalemia (\%) & 0 & 0 & 1 \\
\hline Increase in creatinine > 0.3 mg/dL (\%) & 58 & 41 & 0.38 \\
\hline Ventricular arrhythmias (\%) & 3.8 & 4 & 1.00 \\
\hline Hemodialysis (\%) & 3.8 & 0 & 1.00 \\
\hline Plus-minus values are means \pm standard deviation. & & \\
\hline
\end{tabular}

Figure 4: Weight change per day in the HCTZ and placebo groups.

Values are reported as mean \pm standard deviation (kg/day). HCTZ: $-1.78 \pm 1.08 \mathrm{~kg} /$ day; placebo: $-1.05 \pm$ $1.51 \mathrm{~kg} /$ day; $p=0.062$.

Figure 5: Diuretic response - weight change for every $40 \mathrm{mg}$ of furosemide in the HCTZ and placebo groups.

Values are reported as mean \pm standard deviation ( $\mathrm{kg} / 40 \mathrm{mg}$ of furosemide). $\mathrm{HCTZ:}-0.74 \pm 0.47 \mathrm{~kg} / 40$ mg; placebo: $-0.33 \pm 0.80 \mathrm{~kg} / 40 \mathrm{mg} ; \mathrm{p}=0.032$. 
There was no difference in length of stay, in-hospital mortality, congestion score, electrolyte disturbances, need for hemodialysis, ventricular arrhythmias, need for vasoactive drugs, and change in natriuretic peptides. Likewise, no difference was found in dyspnea or thirst between the groups. In absolute values, there was an increase in creatinine with borderline significance (HCTZ: $0.50 \pm 0.37$ vs placebo: $0.27 \pm$ $0.40 ; p=0.05$ ). However, when comparing an increase in creatinine $>0.3 \mathrm{mg} / \mathrm{dL}$, there was no statistically significant difference between the groups (HCTZ: $58 \%$ vs placebo: $41 \% ; p=0.38$ ) (Table 3 ).

\section{Discussion}

This randomized, placebo-controlled clinical trial evaluated the effect of adding HCTZ to usual treatment in patients with ADHF. We have demonstrated that the mean daily weight loss, for the first three days of admission, were $0,6 \mathrm{Kg} /$ day higher than in placebo group. For each $40 \mathrm{mg}$ of intravenous furosemide used in the treatment of ADHF, HCTZ provided a statistically significant additional effect of $0.4 \mathrm{~kg} /$ day. Diuretic response at the beginning of ADHF therapy has been associated, with less symptoms, better quality of life (15), less signs of congestion (16), less admissions (8), and with reduced mortality (18). Our study has found a better diuretic response on the first days of therapy by adding HCTZ 50 mg per day to the usual care of patients with ADHF. When our data, based on the effect of adding HCTZ on weight change for each $40 \mathrm{mg}$ of furosemide, is compared to data of a larger study investigating prognosis of diuretic response, regardless of HCTZ use or not, we have found that our data perfectly match with Valente's data (18). We, therefore, could possibly raise the hypothesis that having a better diuretic response at the early phase of therapy, by adding HCTZ, could possibly positively impact on patients' prognosis (Fig. 6).

Figure 6: Effect of adding Hydrochlorothiazide (in our trial) plotted over Valente et al. data estimation of mortality based on diuretic response.

Adapted from Valente MAE et al. (18), which suggested lower mortality with greater diuretic response.

Other diuretics have been investigated in the setting of ADHF. Initial data were encouraging for the use of spironolactone in a diuretic dose, suggesting that it could translate into less signs of congestion and lower levels of natriuretic peptides (19). Moreover, spironolactone was found to be a predictor of diuretic response (18). The ATHENA-HF (Aldosterone Targeted Neurohormonal Combined with Natriuresis Therapy in Heart Failure) trial was then conducted to assess spironolactone $100 \mathrm{mg}$ added to usual treatment of $A D H F$, and previous findings were not confirmed. There was no reduction in natriuretic peptides nor was there any additional weight loss when compared to placebo (20).

The use of loop diuretics for the management of ADHF is well established. In the DOSE study, a comparison between high and low diuretic doses showed no differences in the primary outcomes of renal function and symptoms nor in weight loss, which was a secondary outcome in the study. However, a post hoc analysis demonstrated a greater use of thiazide diuretics in patients in the low-dose furosemide group, with a trend towards statistical significance (15). Such finding might be an explanation for neutrality in that study and adds another element to confirm the findings of our study. 
Our study has some limitations. It was a single-center study with a relatively small number of patients. Significance was not reached because the standard deviation was larger than predicted in sample size calculation, based on a previous study (17). Although the primary outcome reached borderline significance, a post hoc analysis adjusted to the dose of intravenous furosemide showed a statistically significant result, which is consistent with the hypothesis of synergy when adding HCTZ to furosemide, with a clinically relevant effect on daily weight loss.

Regarding safety outcomes, there was a greater change in creatinine levels in patients using HCTZ. However, there was no difference between the groups when analyzing onset of acute renal failure, defined as an increase in creatinine $>0.3 \mathrm{mg} / \mathrm{dL}$. According to previous studies, increased creatinine is not related to poor prognosis when patients have reduced congestion $(18,21)$, which occurred more consistently in patients using HCTZ. In terms of quality of life during the process of compensation in ADHF, there was no difference in thirst between the groups. In a previous study of patients with ADHF, thirst was exacerbated during a non-pharmacologic intervention targeting decongestion (22).

Other congestion-related data did not differ between the groups; however, congestion is difficult to assess. The development of new technologies for assessing congestion will contribute to the definition of outcomes in future studies. Moreover, there was neither quantification of diuresis nor assessment of fractional excretion of sodium, which are difficult to measure in an emergency room setting, where the study was conducted. Our HCTZ study was designed to assess weight reduction, with no power for hard outcomes. However, the result could be interpreted as a promising one for ADHF patients.

\section{Conclusions}

For the primary outcome of our study, there was a trend towards greater daily weight loss within 3 days in the HCTZ group compared to the placebo group. In analysis adjusted to the dose of intravenous furosemide, adding HCTZ $50 \mathrm{mg}$ to usual treatment resulted in a synergistic effect on weight loss, with a significant increase in the diuretic effect for every $40 \mathrm{mg}$ of intravenous furosemide used in patients with ADHF.

\section{Abbreviations}

ADHF

Acute decompensated heart failure; ACEl:angiotensin-converting enzyme inhibitor; ARB:angiotensin II receptor blocker; ATHENA-HF:Aldosterone Targeted Neurohormonal Combined with Natriuresis Therapy in Heart Failure trial; CRT:cardiac resynchronization therapy; DOSE:Diuretic Strategies in Patients with Acute Decompensated Heart Failure trial; HCTZ:hydrochlorothiazide; ICD:implantable cardioverter-defibrillator; NYHA:New York Heart Association classification; RAAS:renin-angiotensin-aldosterone system.

\section{Declarations}




\section{Conflicts of interest:}

None declared.

\section{Funding sources:}

None.

\section{References}

1. Heart Failure Society of America. HFSA 2010 Comprehensive Heart Failure Practice Guideline. J Card Fail. 16 (6), e1-2 (2010).

2. Virani, S. S. et al. Heart Disease and Stroke Statistics-2020 Update: A Report From the American Heart Association. Circulation. 141 (9), https://doi.org/10.1161/CIR.0000000000000757 (2020).

3. de Albuquerque, D. C. et al. I Brazilian Registry of Heart Failure - Clinical Aspects, Care Quality and Hospitalization Outcomes. Arq Bras Cardiol. 104 (6), 433-442 (2015).

4. Rohde, L. E. et al. Health outcomes in decompensated congestive heart failure: a comparison of tertiary hospitals in Brazil and United States. Int J Cardiol. 102 (1), 71-77 (2005).

5. Jentzer, J. C., DeWald, T. A. \& Hernandez, A. F. Combination of Loop Diuretics With Thiazide-Type Diuretics in Heart Failure. J Am Coll Cardiol. 56 (19), 1527-1534 (2010).

6. Givertz, M. M. et al. Acute Decompensated Heart Failure: Update on New and Emerging Evidence and Directions for Future Research. J Card Fail. 19 (6), 371-389 (2013).

7. Nohria, A. et al. Clinical assessment identifies hemodynamic profiles that predict outcomes in patients admitted with heart failure. J Am Coll Cardiol. 41 (10), 1797-1804 (2003).

8. Beck-da-Silva, L. et al. Persistent Orthopnea and the Prognosis of Patients in the Heart Failure Clinic. Congest Heart Fail. 10 (4), 177-180 (2004).

9. Verbrugge, F. H. et al. Abdominal Contributions to Cardiorenal Dysfunction in Congestive Heart Failure. J Am Coll Cardiol. 62 (6), 485-495 (2013).

10. Dandamudi, S. \& Chen, H. H. Evolving Treatment Strategies for Management of Cardiorenal Syndrome. Curr Treat Options Cardiovasc Med. 13 (6), 556-569 (2011).

11. Ellison, D. H. \& Felker, G. M. Diuretic Treatment in Heart Failure. Ingelfinger JR, editorN Engl J Med. 2017;377(20):1964-75.

12. Martens, P., Nijst, P. \& Mullens, W. Current Approach to Decongestive Therapy in Acute Heart Failure. Curr Heart Fail Rep. 12 (6), 367-378 (2015).

13. Mullens, W. et al. The use of diuretics in heart failure with congestion - a position statement from the Heart Failure Association of the European Society of Cardiology: Diuretics in heart failure. Eur $J$ Heart Fail. 21 (2), 137-155 (2019). 
14. Mentz, R. J. et al. Decongestion in acute heart failure: Decongestion in heart failure. Eur J Heart Fail. 16 (5), 471-482 (2014).

15. Felker, G. M. et al. Diuretic Strategies in Patients with Acute Decompensated Heart Failure. N Engl J Med. 364 (9), 797-805 (2011).

16. Rohde, L. E. et al. Reliability and prognostic value of traditional signs and symptoms in outpatients with congestive heart failure. Can J Cardiol. 20 (7), 697-702 (2004).

17. Dormans, T. P. J. \& Gerlag, P. G. G. Combination of high-dose furosemide and hydrochlorothiazide in the treatment of refractory congestive heart failure. Eur Heart J. 17 (12), 1867-1874 (1996).

18. Valente, M. A. E. et al. Diuretic response in acute heart failure: clinical characteristics and prognostic significance. Eur Heart J. 35 (19), 1284-1293 (2014).

19. Ferreira, J. P. et al. Mineralocorticoid receptor antagonism in acutely decompensated chronic heart failure. Eur J Intern Med. 25 (1), 67-72 (2014).

20. Butler, J. et al. Efficacy and Safety of Spironolactone in Acute Heart Failure: The ATHENA-HF Randomized Clinical Trial. JAMA Cardiol. 2 (9), 950-958 (2017).

21. Metra, M. et al. Is Worsening Renal Function an Ominous Prognostic Sign in Patients With Acute Heart Failure?: The Role of Congestion and Its Interaction With Renal Function. Circ Heart Fail. 5 (1), 54-62 (2012).

22. Aliti, G. B. et al. Aggressive Fluid and Sodium Restriction in Acute Decompensated Heart Failure: A Randomized Clinical Trial. JAMA Intern Med. 173 (12), 1058 (2013).

\section{Unsectioned Paragraphs}

Effect of adding hydrochlorothiazide to usual treatment of patients with acute decompensated heart failure: a randomized clinical trial

Trial registration: The Brazilian Clinical Trials Registry (ReBEC), a publically accessible primary register that participates in the World Health Organization International Clinical Trial Registry Platform; number RBR-5qkn8h. Registered in 23/07/2019 (retrospectively), http://www.ensaiosclinicos.gov.br/rg/RBR$5 q k n 8 h /$

\section{Figures}




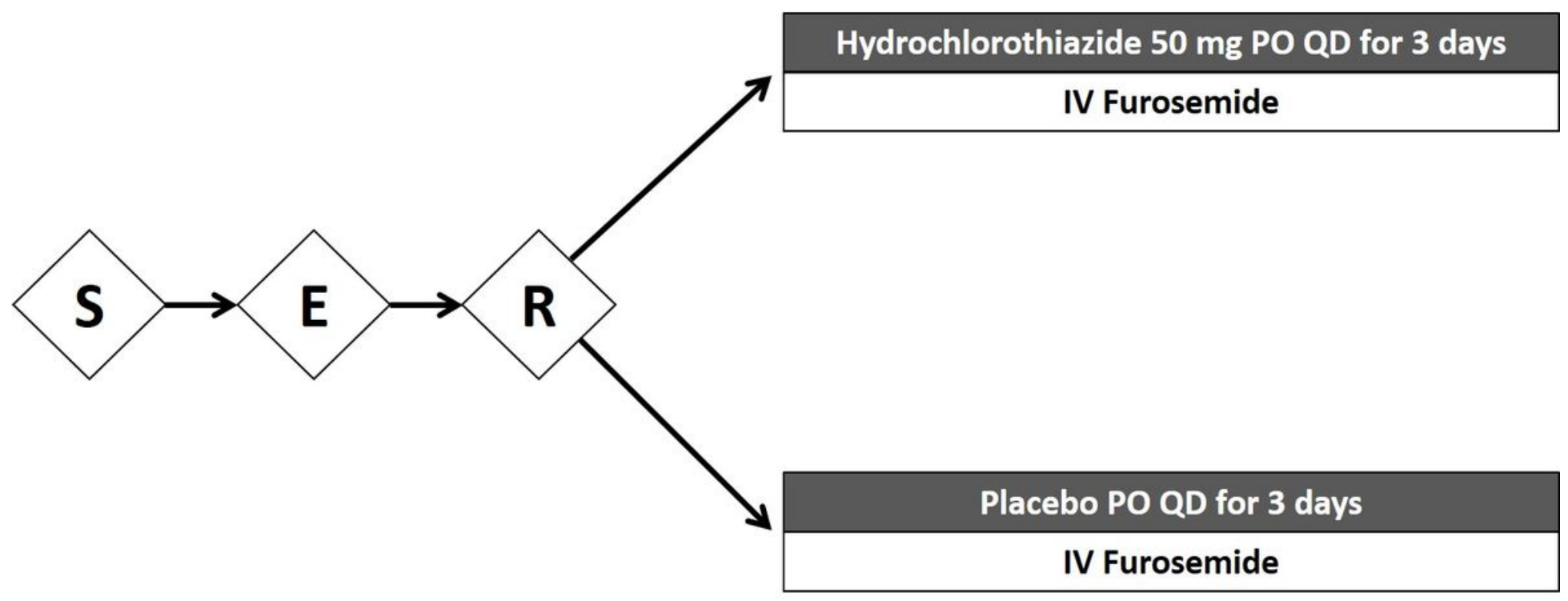

Figure 1

Logistics and interventions S: screening; E: enrollment; R: randomization; PO: oral administration; QD: once daily

\begin{tabular}{|c|}
\hline Inclusion \\
\hline Randomization \\
\hline
\end{tabular}

Drug administration - HCTZ or placebo

Clinical evaluation

Laboratory tests

\section{Patient weighing}

Reassessment of interventions

Review of safety outcomes

\begin{tabular}{|l|c|c|c|c|}
\hline \multicolumn{5}{|c|}{ Lenght of stay } \\
\hline Day 0 & Day 1 & Day 2 & Day 3 & Discharge
\end{tabular}

Figure 2

Study flow diagram 


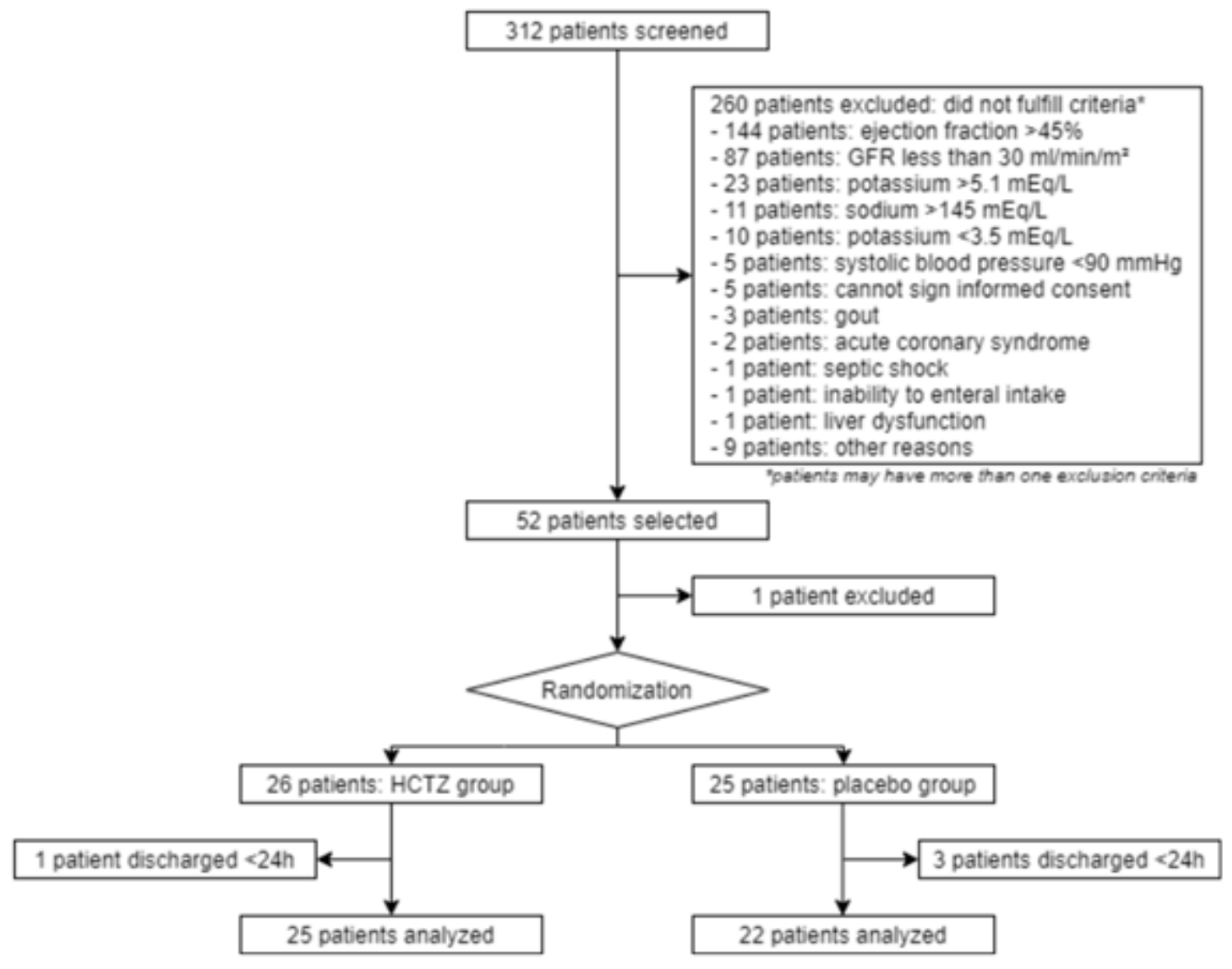

\section{Figure 3}

Study flow diagram 


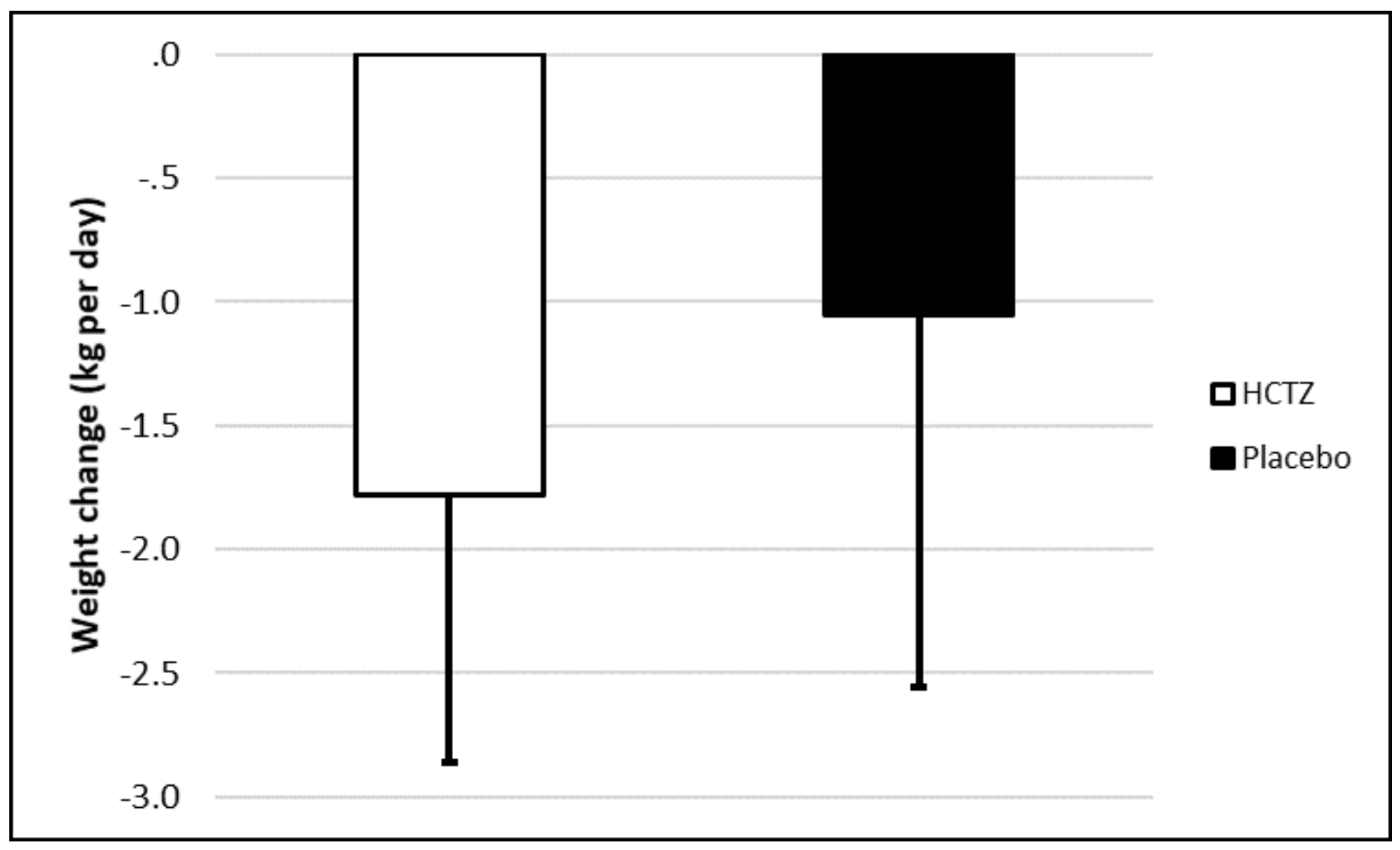

Figure 4

Weight change per day in the HCTZ and placebo groups. Values are reported as mean \pm standard deviation (kg/day). HCTZ: -1.78 \pm 1.08 kg/day; placebo: $-1.05 \pm 1.51$ kg/day; $p=0.062$. 


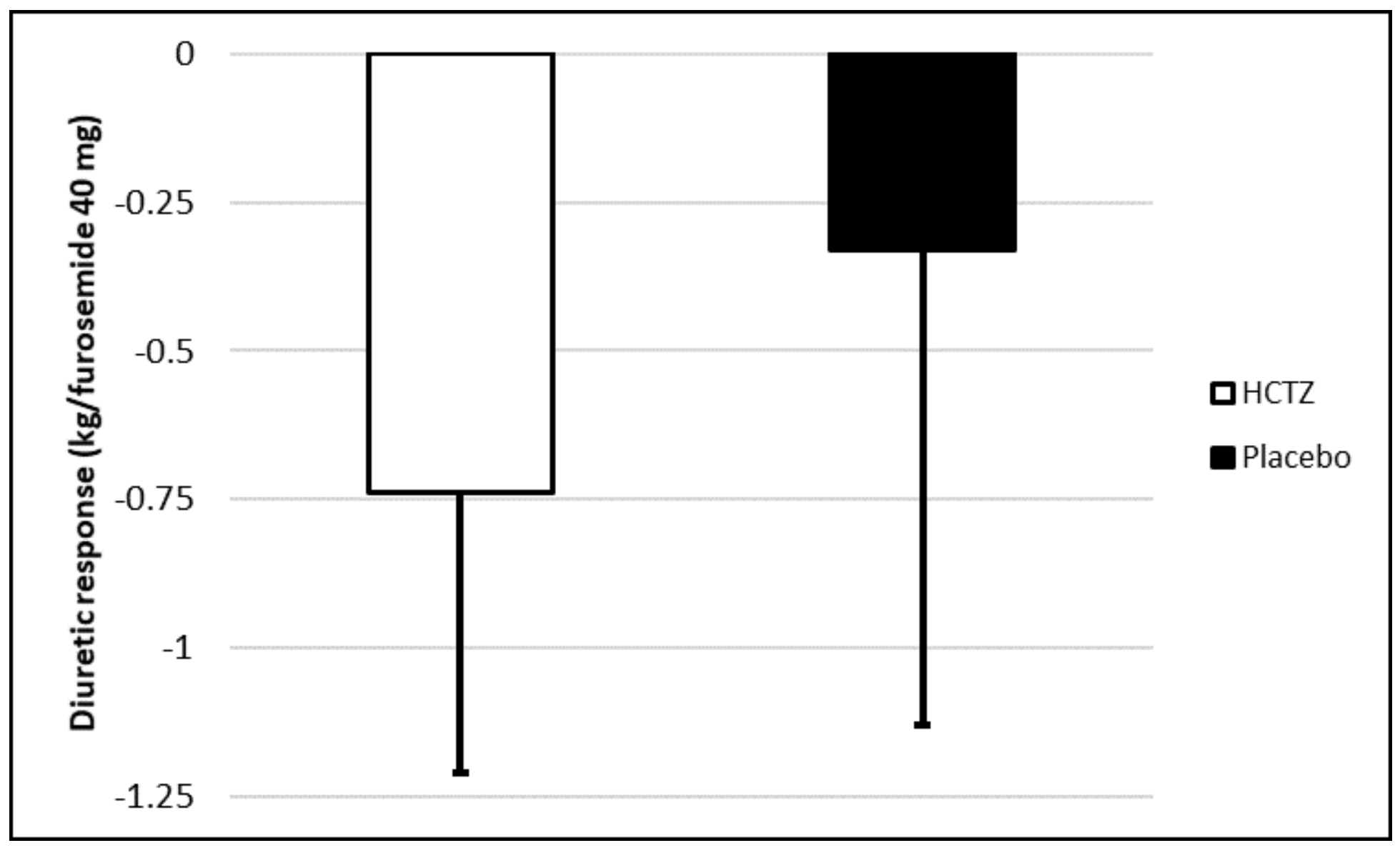

Figure 5

Diuretic response - weight change for every $40 \mathrm{mg}$ of furosemide in the HCTZ and placebo groups. Values are reported as mean \pm standard deviation ( $\mathrm{kg} / 40 \mathrm{mg}$ of furosemide). HCTZ: $-0.74 \pm 0.47 \mathrm{~kg} / 40 \mathrm{mg}$; placebo: $-0.33 \pm 0.80 \mathrm{~kg} / 40 \mathrm{mg} ; \mathrm{p}=0.032$. 


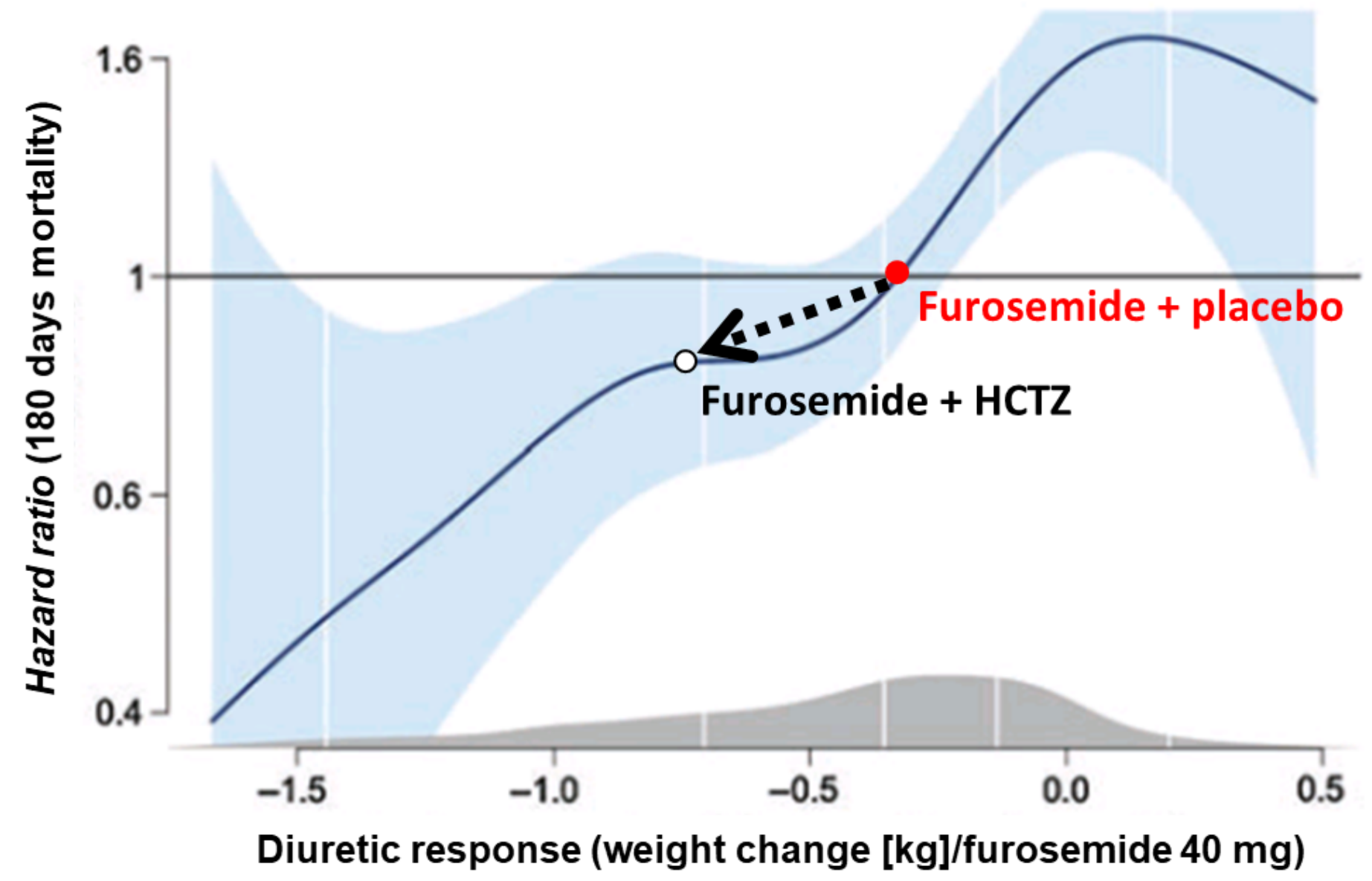

Figure 6

Effect of adding Hydrochlorothiazide (in our trial) plotted over Valente et al. data estimation of mortality based on diuretic response. Adapted from Valente MAE et al. (18), which suggested lower mortality with greater diuretic response. 